Article

\title{
Green Valorization of Olive Leaves to Produce Polyphenol-Enriched Extracts Using an Environmentally Benign Deep Eutectic Solvent
}

\author{
Olga Kaltsa ${ }^{1}$, Spyros Grigorakis ${ }^{2}$, Achillia Lakka ${ }^{1}$, Eleni Bozinou ${ }^{1}$, Stavros Lalas ${ }^{1} @$ and \\ Dimitris P. Makris $1, *$ (D) \\ 1 School of Agricultural Sciences, University of Thessaly, N. Temponera Street, 43100 Karditsa, Greece \\ 2 Food Quality \& Chemistry of Natural Products, Mediterranean Agronomic Institute of Chania (M. A. I. Ch.), \\ International Centre for Advanced Mediterranean Agronomic Studies (CIHEAM), P.O. Box 85, \\ 73100 Chania, Greece \\ * Correspondence: dimitrismakris@uth.gr; Tel.: +30-24410-64792
}

Received: 17 March 2020; Accepted: 30 March 2020; Published: 1 April 2020

check for updates

\begin{abstract}
Olive leaves (OLL) are considered to be a highly appreciated bioresource of bioactive polyphenolic phytochemicals, embracing several different structures. However, extraction processes based on deep eutectic solvents (DES) are very limited despite the wide range of techniques developed for the efficient recovery of polyphenols. This study had as objective the development of a simple, green, high-performance extraction methodology for OLL polyphenols, using a recently reported effective DES, composed of L-lactic acid and glycine. Initially, a screening was performed to select the most appropriate L-lactic/glycine molar ratio and process optimization was then carried out with response surface methodology. The optimized process variable values were DES/water $(78 \%$ $\mathrm{w} / \mathrm{v}$ ), liquid-to-solid ratio of $36 \mathrm{~mL} \mathrm{~g}^{-1}$, and stirring speed of 500 rounds per minute, and the total polyphenol yield amounted to $97.53 \pm 3.54 \mathrm{mg}$ gallic acid equivalents per g dry matter. Extraction with DES at $80^{\circ} \mathrm{C}$ did not significantly increase the total polyphenol yield, but it did enhance the total flavonoid yield and antioxidant activity. High-performance liquid chromatography analyses revealed that extraction with the DES resulted in extended oleuropein hydrolysis, to the favor of hydroxytyrosol formation. This finding might have a prospect in using properly tuned DES for polyphenol modification with improved bioactivities.
\end{abstract}

Keywords: deep eutectic solvents; extraction; olive leaves; polyphenols; waste valorization

\section{Introduction}

Food production inevitably leads to waste generation at every processing stage. This residual biomass is mostly composed of organic substances and it is characterized by a significant polluting load, high moisture content, variable composition, and creates disposal management problems of paramount importance [1]. On the other hand, food production side-streams have now been greatly acknowledged as key bioresources of value-added substances with high prospects in food, cosmetics, chemical, and pharmaceutical industry. Thus, separation processes that are based on eco-friendly technologies for the recovery of bioactive natural products from agro-industrial waste is particularly attractive, while taking both socio-environmental and economic aspects into account [2].

Contemporary trends in green extraction techniques mainly pertain to the minimization of solvent use, processes with low-energy requirements, and novel eco-friendly materials that are environmentally benign. The strongest scientific tendencies that are related to sustainable perspectives of natural product separation from waste are those addressing the issue of solvent selection [3,4]. Selection 
is principally associated with the green profile of the process as a whole, and critical parameters, such as the physical-chemical characteristics of the compounds of interest, selectivity, high recovery yields, and stability of the target compounds, are the key criteria considered. On such a basis, deep eutectic solvents (DES) are promising materials, which are characterized by several advantages over conventional, volatile solvents of petrochemical origin. DES are designer liquids and their synthesis is facile and straight-forward, requiring food-compatible, inexpensive constituents, such as organic acids and organic acid salts, amino acids, polyols, sugars, etc. Currently, DES are gaining wide acceptance as promising green solvents, due to features, including the absence of toxicity, biodegradability, and recyclability [5]. Furthermore, DES composition might be tunable, thus making possible regulation of their physicochemical properties and widening the spectrum of applicability for natural product extraction [6].

Olive leaves (OLL) are agri-food residues that originate from the olive processing and it has been estimated that olive oil production might yield approximately $10 \%$ of leaves as waste, of the total weight of olives processed at the mills [7]. Olive leaf extracts have been proven to exhibit a multitude of bioactivies, and numerous techniques that are based on conventional solvents (water, ethanol, and methanol) have been developed. However, there has been a few recent studies dealing with olive leaf extraction with DES and the data that are available in the literature are quite limited in this regard. In this framework, this study was undertaken to develop a green and highly efficient extraction process for OLL polyphenols, using a high-performing DES, synthesized with glycine and L-lactic acid [8]. The process design was implemente using response surface methodology and extraction appraisal was based on total polyphenol yield, in vitro antioxidant properties of the extracts, as well as the profiling of major polyphenolic metabolites.

\section{Materials and Methods}

\subsection{Chemicals}

All of the solvents used for chromatography were HPLC grade. Glycine (Gly) $(99.5 \%)$ was from Applichem (Darmstadt, Germany). Sodium carbonate anhydrous (99\%), L-lactic acid (LA), ascorbic acid (99.5\%), and aluminium chloride anhydrous (98\%) were from Penta (Praha, Czechia). Rutin hydrate, luteolin 7-O-glucoside, hydroxytyrosol ( $\geq 98 \%$ ), oleuropein (98\%), 2,4,6-tris(2-pyridyl)-s-triazine (TPTZ), quercetin, 2,2-diphenylpicrylhydrazyl (DPPH), and Folin-Ciocalteu reagent were from Sigma-Aldrich (St. Louis, MO, U.S.A.). Iron chloride hexahydrate was from Merck (Darmstadt, Germany). Gallic acid hydrate was from Panreac (Barcelona, Spain).

\subsection{Collection of Plant Material and Handling}

The olive leaves (OLL) were from Agrielia Kalamon variety (Olea europaea L.) and they were collected from an olive tree plantation at the region of Avlida (Evia, Central Greece), following a practice that ensured minimum variation in composition due to differences in exposure to sunlight [9]. The leaves were transported to the laboratory within $3-4 \mathrm{~h}$ and then dried at $55^{\circ} \mathrm{C}$ for $24 \mathrm{~h}$. Dried OLL were pulverized in a ball-mill to give a powder with average particle diameter of $0.102 \mathrm{~mm}$, and then stored in air-tight containers, at $18^{\circ} \mathrm{C}$.

\subsection{Synthesis of DES}

A previously published protocol was employed to synthesize the DES tested [8]. Exact mass of glycine (hydrogen bond acceptor-HBA) and L-lactic acid (hydrogen bond donor-HBD) was introduced into a round-bottom glass flask and then heated in oil bath placed on a temperature-controlled hotplate (Witeg, Wertheim, Germany) for $120 \mathrm{~min}$., at $80{ }^{\circ} \mathrm{C}$, to form a transparent liquid. The liquid was left to reach ambient temperature and then placed in a sealed vial, in the dark. All of the samples were periodically inspected for crystal appearance (instability indication) over six weeks. 


\subsection{Batch Stirred-Tank Extraction}

The DES that were used for the extractions were assayed as $70 \%(\mathrm{w} / \mathrm{v})$ aqueous mixtures. Control extractions were performed with $60 \%(\mathrm{v} / \mathrm{v})$ aqueous ethanol, deionised water and $60 \%(\mathrm{v} / \mathrm{v})$ aqueous methanol. A precise amount of $0.570 \mathrm{~g}$ of dried OLL was transferred along with $20 \mathrm{~mL}$ of solvent into a 50-mL round-bottom flask, and the flask was then immersed into heated oil bath. Extractions were performed under magnetic stirring set at $500 \mathrm{rpm}$, at $50{ }^{\circ} \mathrm{C}$, for $150 \mathrm{~min}$., followed by centrifugation for 10 min., at $10,000 \times g$.

\subsection{Design of Experiment-Response Surface Methodology}

The implemented design was a Box-Behnken with three central points. The process (independent) variables used to build the design were the proportion of DES/water $\left(C_{D E S}\right)$, the stirring speed $\left(S_{S}\right)$, and the liquid-to-solid ratio $\left(\mathrm{R}_{\mathrm{L} / \mathrm{S}}\right)$. These specific variables were selected on the ground of the outcome of recent investigations, which highlighted their importance in polyphenol extraction performance [10,11]. The variables $C_{D E S}, R_{L / S}$, and $S_{S}$ were termed as $X_{1}, X_{2}$, and $X_{3}$, respectively, and coded between -1 (lower limit) and +1 (upper limit) (Table 1 ). The following equation was used for the codification:

$$
\mathrm{X}_{\mathrm{i}}=\left(\frac{z_{i}-z_{1}^{0}}{\Delta z_{i}}\right) \times \beta_{\mathrm{d}}
$$

where $\Delta z_{\mathrm{i}}$ is the distance between the actual (real) value at the central point and that in the upper or lower limit of a variable, $\beta_{\mathrm{d}}$ is the major coded limit value in the matrix for each variable, and $z^{0}$ corresponds to the actual value at the central point. The model (polynomial equation) was generated by fitting the function to the experimental data, and the model appraisal was based on lack-of-fit and ANOVA. The model was visualized by three-dimensional (3D) surface response plots.

Table 1. The process variables included in the experimental design with the corresponding code units and coded levels.

\begin{tabular}{ccccc}
\hline Independent Variables & Code Units & \multicolumn{3}{c}{ Coded Variable Level } \\
\hline & & $\mathbf{- 1}$ & $\mathbf{0}$ & $\mathbf{1}$ \\
\hline $\mathrm{C}_{\mathrm{DES}}(\%, \mathrm{w} / \mathrm{v})$ & $\mathrm{X}_{1}$ & 55 & 70 & 85 \\
$\mathrm{R}_{\mathrm{L} / \mathrm{S}}\left(\mathrm{mL} \mathrm{g}^{-1}\right)$ & $\mathrm{X}_{2}$ & 20 & 40 & 60 \\
$\mathrm{~S}_{\mathrm{S}}(\mathrm{rpm})$ & $\mathrm{X}_{3}$ & 200 & 500 & 800 \\
\hline
\end{tabular}

\subsection{Total Polyphenol Determination}

A validated protocol was used [12]. Prior to analysis, $0.5 \%$ aqueous formic acid was used to dilute samples 1:50. Subsequently, $0.1 \mathrm{~mL}$ of sample was mixed with $0.1 \mathrm{~mL}$ Folin-Ciocalteu reagent in a 1.5-mL Eppendorf tube. After $2 \mathrm{~min}$. of reaction, $0.8 \mathrm{~mL}$ of sodium carbonate $(5 \% \mathrm{w} / \mathrm{v})$ was added, and the mixture was incubated for a period of $20 \mathrm{~min}$., at $40{ }^{\circ} \mathrm{C}$, in a water bath. The absorbance at $740 \mathrm{~nm}$ was recorded and a calibration curve constructed with gallic acid (10-80 $\mathrm{mg} \mathrm{L}^{-1}$ ) was used for the determination of total polyphenol concentration $\left(C_{\mathrm{TP}}\right)$. The yield in total polyphenols $\left(\mathrm{Y}_{\mathrm{TP}}\right)$ was expressed as mg gallic acid equivalents (GAE) per g dry mass (dm).

\subsection{Total Flavonoid Determination}

For total flavonoid determination, a previously described methodology was used [13]. The reagent $(0.04 \mathrm{~mL})$ consisted of $5 \%(\mathrm{w} / \mathrm{v}) \mathrm{AlCl}_{3}$ and $0.5 \mathrm{M} \mathrm{CH}_{3} \mathrm{COONa}$, was mixed with $0.86 \mathrm{~mL} \mathrm{35 \%} \mathrm{(v/v)}$ aqueous ethanol and diluted sample $(0.1 \mathrm{~mL})$ and. The absorbance was red at $415 \mathrm{~nm}$ following incubation for $30 \mathrm{~min}$ at room temperature. A calibration curve using rutin as standard (15-300 $\left.\mathrm{mg} \mathrm{L}^{-1}\right)$ was used to determine the total flavonoid concentration $\left(C_{\mathrm{TFn}}\right)$, and yield in total flavonoids $\left(\mathrm{Y}_{\mathrm{TFn}}\right)$ was calculated as $\mathrm{mg}$ rutin equivalents (RtE) per $\mathrm{g} \mathrm{dm}$. 


\subsection{Antiradical Activity $\left(A_{A R}\right)$ Determination}

A previously described DPPH assay was used [14]. The samples were diluted 1:50 with methanol prior to the analysis, and then $0.975 \mathrm{~mL}$ DPPH $(100 \mu \mathrm{M}$ in methanol) was mixed with $0.025 \mathrm{~mL}$ of sample. The absorbance was obtained at $515 \mathrm{~nm}$ immediately after mixing $(t=0 \mathrm{~min}$.) and after $30 \mathrm{~min}$. $(t=30 \mathrm{~min}$.$) . The \mathrm{A}_{\mathrm{AR}}$ of the extract was determined, as follows:

$$
\mathrm{A}_{\mathrm{AR}}=\frac{C_{\mathrm{DPPH}}}{C_{\mathrm{TP}}} \times\left(1-\frac{\mathrm{A}_{515(\mathrm{f})}}{\mathrm{A}_{515(\mathrm{i})}}\right) \times \mathrm{Y}_{\mathrm{TP}}
$$

where $C_{\mathrm{DPPH}}$ is the DPPH concentration $(\mu \mathrm{M})$ and $C_{\mathrm{TP}}$ the total polyphenol concentration $\left(\mathrm{mg} \mathrm{L}^{-1}\right)$ in the reaction mixture, respectively. $A_{515(\mathrm{f})}$ represents the $A_{515}$ at $t=30 \mathrm{~min}$. and $A_{515(\mathrm{i})}$ the $A_{515}$ at $t=0$. $\mathrm{Y}_{\mathrm{TP}}$ corresponds to the extraction yield $\left(\mathrm{mg} \mathrm{g}^{-1}\right)$ in TP. $\mathrm{A}_{\mathrm{AR}}$ was determined as $\mu \mathrm{mol} \mathrm{DPPH} \mathrm{g}{ }^{-1} \mathrm{dm}$.

\subsection{Ferric-Reducing Power $\left(P_{R}\right)$ Determination}

The assay was carried out as previously described [14]. The samples were diluted 1:50 with deionized water and $0.05 \mathrm{~mL}$ was mixed with $0.05 \mathrm{~mL} \mathrm{FeCl}_{3}(4 \mathrm{mM}$ in $0.05 \mathrm{M} \mathrm{HCl})$, and incubated in a water bath for $30 \mathrm{~min}$, at $37^{\circ} \mathrm{C}$. Subsequently, $0.9 \mathrm{~mL}$ of TPTZ solution ( $1 \mathrm{mM}$ in $\left.0.05 \mathrm{M} \mathrm{HCl}\right)$ was added followed by incubation for $5 \mathrm{~min}$., at room temperature. $\mathrm{P}_{\mathrm{R}}$ was determined as $\mu \mathrm{mol}$ ascorbic acid equivalents (AAE) $\mathrm{g}^{-1} \mathrm{dm}$, after reading the absorbance at $620 \mathrm{~nm}$, with an ascorbic acid calibration curve $(50-300 \mu \mathrm{M})$.

\subsection{Liquid Chromatography-Diode Array-Mass Spectrometry (LC-DAD-MS)}

The analyses were carried out on the basis of a previous methodology [15]. The chromatograph was a Finnigan P4000 pump, a UV6000LP diode array detector, and a Finnigan AQA mass spectrometer (San Jose, CA, USA). Chromatography was performed with a $10-\mu \mathrm{L}$ injection loop, using a Fortis RP-18 column, $150 \mathrm{~mm} \times 2.1 \mathrm{~mm}, 3 \mu \mathrm{m}$, at $40^{\circ} \mathrm{C}$, with a flow rate of $0.3 \mathrm{~mL} \mathrm{~min} .^{-1}$. Mass spectra acquisition was done with electrospray ionisation (ESI) in positive ion mode at 10 and $50 \mathrm{eV}$. Source voltage was set at $25 \mathrm{~V}$, capillary voltage at $4 \mathrm{kV}$, detector voltage at $650 \mathrm{~V}$, and the probe temperature was $250{ }^{\circ} \mathrm{C}$. The eluents were (A) $2 \%$ acetic acid and (B) methanol and the elution program was 0-30 min., 0-100\% methanol, 30-40 min., and 100\% methanol.

\subsection{High-Performance Liquid Chromatography (HPLC)}

A methodology previously described was implemented [8]. Chromatographic analyses were carried with a Shimadzu CBM-20A liquid chromatograph (Shimadzu Europa GmbH, Duisburg, Germany), coupled to a Shimadzu SPD-M20A detector, and interfaced by Shimadzu LC solution software. The column was a Phenomenex Luna C18(2) $(100 \AA$, $5 \mu \mathrm{m}, 4.6 \times 250 \mathrm{~mm})$ (Phenomenex, Inc., Torrance, CA, USA), bearing a precolumn of the same material. Analysis temperature was set at $40{ }^{\circ} \mathrm{C}$ and chromatography was performed with (A) $0.5 \%$ aqueous formic acid and (B) $0.5 \%$ formic acid in $\mathrm{MeCN} /$ water (6:4) as eluents. The flow rate was $1 \mathrm{~mL} \mathrm{min.}{ }^{-1}$ and the injected volume $20 \mu \mathrm{L}$. The elution program used was: $100 \%$ A to $60 \% \mathrm{~A}$ in $40 \mathrm{~min}$.; $60 \% \mathrm{~A}$ to $50 \% \mathrm{~A}$ in $10 \mathrm{~min}$.; $50 \% \mathrm{~A}$ to $30 \% \mathrm{~A}$ in $10 \mathrm{~min}$. , which was kept constant for another $10 \mathrm{~min}$. Quantification was done with calibration curves $\left(0-50 \mu \mathrm{g} \mathrm{mL}{ }^{-1}\right)$ constructed with hydroxytyrosol $\left(R^{2}=0.9990\right)$, luteolin 7-O-glucoside $\left(R^{2}=0.9980\right)$, oleuropein $\left(R^{2}=0.9990\right)$, quercetin $\left(R^{2}=0.9990\right)$, and apigenin $\left(R^{2}=0.9999\right)$. Hydroxytyrosol and oleuropein were quantified at $280 \mathrm{~nm}$, luteolin 7-O-glucoside and apigenin at $345 \mathrm{~nm}$, and rutin and quercetin at $360 \mathrm{~nm}$.

\subsection{Statistical Analysis}

The extraction procedures were performed twice and all determinations in triplicate. Results are reported as average \pm standard deviation (sd). Linear correlations were performed with linear 
regression analysis using SigmaPlot ${ }^{\mathrm{TM}}$ (Systat Software Inc., San Jose, CA, USA). 12.5, at a 95\% significance level $(p<0.05)$. The design of experiment, response surface methodology, and all relevant statistics (lack-of-fit, ANOVA) were done with JMPTM Pro 13.

\section{Results and Discussion}

\subsection{Effect of DES Composition}

One of the main intrinsic features that provides tunability to DES is the capability of varying HBD:HBA molar ratio $\left(R_{\text {mol }}^{\mathrm{D} / \mathrm{A}}\right)$. Switching $\mathrm{R}_{\mathrm{mol}}^{\mathrm{D} / \mathrm{A}}$ affects DES key properties for an extraction process, such as polarity and viscosity [16]. DES composed of LA and Gly have been recently used for polyphenol extraction from saffron processing wastes [8], where the influence of $R_{\text {mol }}^{\mathrm{D} / \mathrm{A}}$ was clearly demonstrated. In this framework, the first stage in testing LA-Gly DES for their effectiveness in recovering OLL polyphenols was to assess the effect of $\mathrm{R}_{\mathrm{mol}}^{\mathrm{D} / \mathrm{A}}$. To this purpose, a series of LA-Gly DES were synthesized, with $R_{\text {mol }}^{\mathrm{D} / \mathrm{A}}$ varying from 5 to 13, and were termed as LA-Gly (5:1), (7:1), (9:1), (11:1), and (13:1). Figure 1 displays the screening results concerning $\mathrm{Y}_{\mathrm{TP}}$.

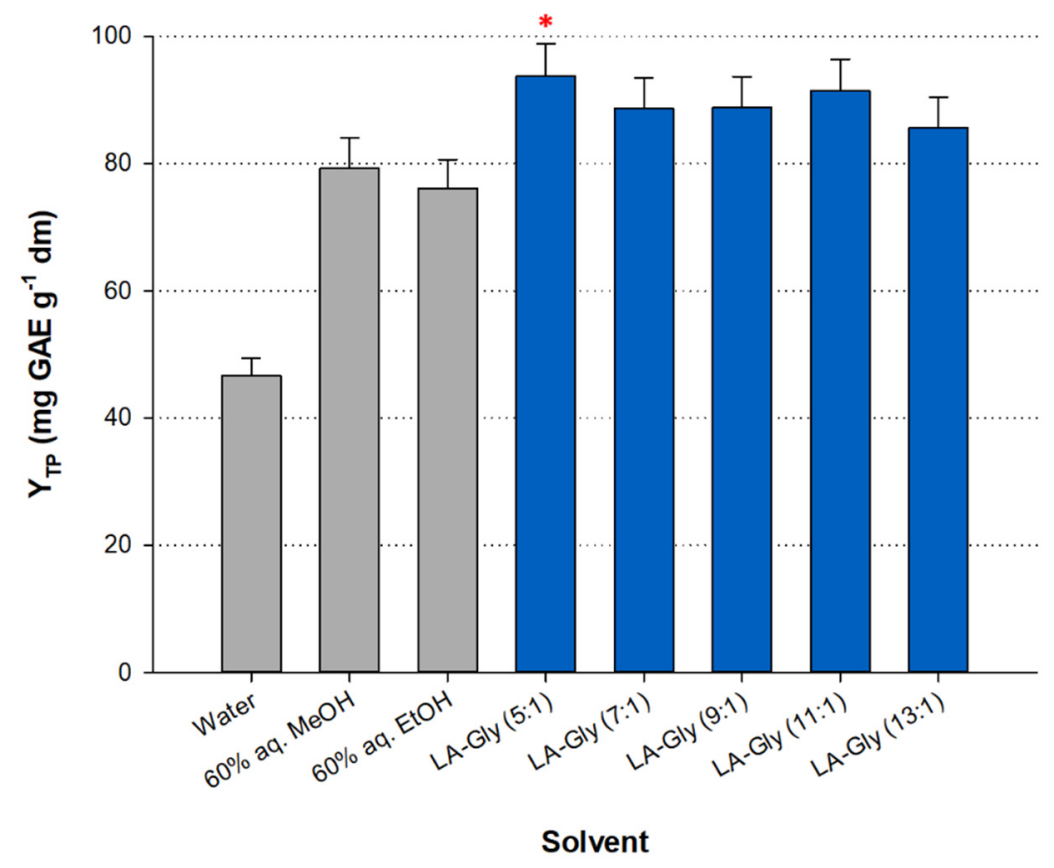

Figure 1. $\mathrm{R}_{\text {mol }}^{\mathrm{D} / \mathrm{A}}$ screening and comparison with control solvents. DES were $70 \%(\mathrm{w} / \mathrm{v})$ aqueous mixtures. Extractions were performed under stirring at $500 \mathrm{rpm}$, for $150 \mathrm{~min}$., at $50{ }^{\circ} \mathrm{C}$. *-the highest YTP $(p<0.05)$.

DES LA-Gly (5:1) exhibited statistically higher $\mathrm{Y}_{\mathrm{TP}}(p<0.05)$, surpassing even $60 \%(\mathrm{v} / \mathrm{v})$ methanol and $60 \%(\mathrm{v} / \mathrm{v})$ ethanol. This finding was in line with the data that were reported for saffron processing wastes, highlighting the potency of LA-Gly (5:1) [8]. However, because using only $\mathrm{Y}_{\mathrm{TP}}$ as the screening response might be a unilateral assessment, the effectiveness of LA-Gly (5:1) was further evaluated by determining $Y_{T F n}, A_{A R}$ and $P_{R}$. LA-Gly (5:1) was shown to provide extracts with significantly higher $\mathrm{A}_{\mathrm{AR}}$ and $\mathrm{P}_{\mathrm{R}}(p<0.05)$, but the highest, though not statistically significant, $\mathrm{Y}_{\mathrm{TFn}}$ was achieved with $60 \%$ $(\mathrm{v} / \mathrm{v})$ ethanol (Table 2). On the ground of this outcome, LA-Gly (5:1) was chosen as the most effective solvent, and it was used for carrying out the optimization of the extraction. 
Table 2. Yields in total polyphenols $\left(\mathrm{Y}_{\mathrm{TP}}\right)$ and total flavonoids $\left(\mathrm{Y}_{\mathrm{TFn}}\right)$, as well as antioxidant characteristics of the extracts produced with La-Gly (5:1) and control solvents.

\begin{tabular}{|c|c|c|c|c|}
\hline Solvent & 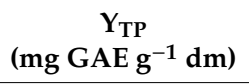 & $\begin{array}{c}\mathrm{Y}_{\mathrm{TFn}} \\
\left.\text { (mg RtE } \mathrm{g}^{-1} \mathrm{dm}\right)\end{array}$ & $\begin{array}{c}\mathrm{A}_{\mathrm{AR}} \\
\left(\mu \mathrm{mol} \mathrm{DPPH} \mathrm{g}^{-1} \mathrm{dm}\right)\end{array}$ & $\begin{array}{c}P_{R} \\
\left(\mu \mathrm{mol} \mathrm{AAE} \mathrm{g}^{-1} \mathrm{dm}\right)\end{array}$ \\
\hline Water & $46.64 \pm 2.80$ & $7.81 \pm 0.47$ & $265.93 \pm 5.32$ & $213.15 \pm 3.20$ \\
\hline $60 \% \mathrm{MeOH}$ & $79.23 \pm 4.75$ & $18.33 \pm 1.10$ & $381.17 \pm 7.62$ & $276.26 \pm 4.14$ \\
\hline $60 \% \mathrm{EtOH}$ & $76.07 \pm 4.56$ & $22.12 \pm 1.33$ & $347.93 \pm 6.96$ & $265.43 \pm 3.98$ \\
\hline LA-Gly (5:1) ${ }^{\mathrm{a}}$ & $93.73 \pm 5.16 *$ & $17.28 \pm 0.95$ & $508.60 \pm 10.17$ * & $400.61 \pm 6.01$ * \\
\hline
\end{tabular}

* Asterisk indicates statistically different value $(p<0.05)$. ${ }^{a}$ Tested as $70 \%(w / v)$ aqueous mixture.

\subsection{Extraction Process Optimization}

The effect the three process variables exerted on the response $\left(\mathrm{Y}_{\mathrm{TP}}\right)$ was modelled by the deployment of response surface methodology. The scope was to fit the model (polynomial equation) to the experimental data, in order to perform reliable predictions. The evaluation of model fitting was based on lack-of-fit and ANOVA tests (Table 3).

Table 3. Statistical information on the model constructed on the basis of Box-Behnken experimental design.

\begin{tabular}{cccccc}
\hline Term & Standard Error & t Ratio & Probability $>\mathbf{t}$ & Sum of Squares & F Ratio \\
\hline$C_{\mathrm{DES}}$ & 0.901165 & 5.44 & $0.0029^{*}$ & 192.17801 & 29.5805 \\
$\mathrm{R}_{\mathrm{L} / \mathrm{S}}$ & 0.901165 & -4.85 & $0.0047^{*}$ & 152.68781 & 23.5020 \\
$\mathrm{~S}_{\mathrm{S}}$ & 0.901165 & -0.78 & 0.4694 & 3.97620 & 0.6120 \\
$\mathrm{C}_{\mathrm{DES}} \mathrm{R}_{\mathrm{L} / \mathrm{S}}$ & 1.27444 & -0.78 & 0.4682 & 4.00000 & 0.6157 \\
$\mathrm{C}_{\mathrm{DES}} \mathrm{S}_{\mathrm{S}}$ & 1.27444 & -0.24 & 0.8218 & 0.36602 & 0.0563 \\
$\mathrm{R}_{\mathrm{L} / \mathrm{S}} \mathrm{S}_{\mathrm{S}}$ & 1.27444 & -3.13 & $0.0259^{*}$ & 63.76023 & 9.8141 \\
$\mathrm{C}_{\mathrm{DES}} \mathrm{C}_{\mathrm{DES}}$ & 1.326479 & -3.61 & $0.0154^{*}$ & 84.74616 & 13.0443 \\
$\mathrm{R}_{\mathrm{L} / \mathrm{S}} \mathrm{R}_{\mathrm{L} / \mathrm{S}}$ & 1.326479 & -8.90 & $0.0003^{*}$ & 514.62536 & 79.2123 \\
$\mathrm{~S}_{\mathrm{S}} \mathrm{S}_{\mathrm{S}}$ & 1.326479 & -2.41 & 0.0611 & 37.65186 & 5.7955 \\
Lack-of-fit & & & 0.3241 & 32.483942 & 2.2340 \\
\hline
\end{tabular}

* Asterisk indicates statistically different value $(p<0.05)$.

Statistically non-significant terms were not taken into account and, thus, the final form of the model was:

$$
\mathrm{Y}_{\mathrm{TP}}=95.77+4.90 \mathrm{X}_{1}-4.37 \mathrm{X}_{2}-3.99 \mathrm{X}_{2} \mathrm{X}_{3}-4.79 \mathrm{X}_{1}^{2}-11.81 \mathrm{X}_{2}^{2}\left(\mathrm{R}^{2}=0.97, p=0.0030\right)
$$

Analytical information regarding the measured and predicted response for the individual design points is provided in Table 4 and Figure 2 portrays model visualization, in the form of Contour plots. Prediction for the optimal conditions to attain maximum $\mathrm{Y}_{\mathrm{TP}}$ was enabled by the use of the desirability function. The predicted optimal values for the independent variables were $C_{\mathrm{DES}}=78 \%(\mathrm{w} / \mathrm{v}), \mathrm{R}_{\mathrm{L} / \mathrm{S}}=36 \mathrm{~mL} \mathrm{~g}^{-1}$, and $\mathrm{S}_{\mathrm{S}}=500 \mathrm{rpm}$, and the maximum predicted response was $97.53 \pm 3.54 \mathrm{mg} \mathrm{GEA} \mathrm{g}^{-1} \mathrm{dm}$. 
Table 4. Experimental design points and corresponding measured and predicted responses.

\begin{tabular}{|c|c|c|c|c|c|}
\hline \multirow[t]{2}{*}{ Design Point } & \multicolumn{3}{|c|}{ Independent Variables } & \multicolumn{2}{|c|}{ Response $\left(\mathrm{Y}_{\mathrm{TP}}, \mathrm{mg} \mathrm{GAE} \mathrm{g}^{-1} \mathrm{dm}\right)$} \\
\hline & $\mathrm{X}_{1}\left(C_{\mathrm{DES}}, \% \mathrm{w} / \mathrm{v}\right)$ & $\mathrm{X}_{2}\left(\mathrm{R}_{\mathrm{L} / \mathrm{S}}, \mathrm{mL} \mathrm{g}^{-1}\right)$ & $X_{3}\left(S_{S}\right.$, rpm $)$ & Measured & Predicted \\
\hline 1 & $-1(55)$ & $-1(20)$ & $0(500)$ & 79.88 & 77.64 \\
\hline 2 & $-1(55)$ & $1(60)$ & $0(500)$ & 71.67 & 70.90 \\
\hline 3 & $1(85)$ & $-1(20)$ & $0(500)$ & 88.67 & 89.44 \\
\hline 4 & $1(85)$ & $1(60)$ & $0(500)$ & 76.46 & 78.70 \\
\hline 5 & $0(70)$ & $-1(20)$ & $-1(200)$ & 80.55 & 81.85 \\
\hline 6 & $0(70)$ & $-1(20)$ & $1(800)$ & 88.25 & 88.42 \\
\hline 7 & $0(70)$ & $1(60)$ & $-1(200)$ & 81.27 & 81.10 \\
\hline 8 & $0(70)$ & $1(60)$ & $1(800)$ & 73.00 & 71.70 \\
\hline 9 & $-1(55)$ & $0(40)$ & $-1(200)$ & 82.34 & 83.28 \\
\hline 10 & $1(85)$ & $0(40)$ & $-1(200)$ & 95.76 & 93.69 \\
\hline 11 & $-1(55)$ & $0(40)$ & $1(800)$ & 80.41 & 82.48 \\
\hline 12 & $1(85)$ & $0(40)$ & $1(800)$ & 92.62 & 91.68 \\
\hline 13 & $0(70)$ & $0(40)$ & $0(500)$ & 93.54 & 95.77 \\
\hline 14 & $0(70)$ & $0(40)$ & $0(500)$ & 97.00 & 95.77 \\
\hline 15 & $0(70)$ & $0(40)$ & $0(500)$ & 96.76 & 95.77 \\
\hline
\end{tabular}

The verification of the prediction was done by running three individual extractions, while using the recommended optimal settings, which gave an average $Y_{T P}$ value of $96.41 \pm 2.27 \mathrm{mg} \mathrm{GAE} \mathrm{g}^{-1} \mathrm{dm}$.

The critical assessment of the information given in Table 3 would point out that the direct role of $S_{S}$ in the extraction performance was insignificant. On the other hand, the significance of the term $X_{2} X_{3}$ might indicate that the effect of changes in $S_{S}$ could be manifested in combination with changes in $R_{L / S}$. This is in agreement with a previous investigation on OLL polyphenol extraction, which showed that $S_{S}$ was not significant, but the cross-term $S_{S} \times R_{L / S}$ was [17]. Similar results have been drawn for onion solid waste polyphenol extraction [18]. Previous examinations supported that both of the variables are virtually associated with diffusivity, since diffusion that is a controlling parameter of a solid-liquid extraction process might depend on both $\mathrm{S}_{\mathrm{S}}$ and $\mathrm{R}_{\mathrm{L} / \mathrm{S}}$.

The driving force of diffusion is the concentration gradient between the solid particles and the liquid phase, which is defined by $\mathrm{R}_{\mathrm{L} / \mathrm{S}}$. Increased $\mathrm{R}_{\mathrm{L} / \mathrm{S}}$ would entail increased concentration gradient and, thus, increased diffusivity $[19,20]$. It has been argued that the amount of the liquid phase should be considerably higher when compared to that of the solid phase, otherwise there might be significant resistance to mass transfer, hence, reduced extraction yield [21]. Therefore, $\mathrm{R}_{\mathrm{L} / \mathrm{S}}$ below a certain limit would not be favorable for increased extraction yield. Likewise, $S_{S}$ should be at a minimum level to ascertain appropriate mixing of the solid particles with the solvent, which in turn would minimize external resistance and contribute in attaining higher diffusivity [22]. Indeed, a recent investigation demonstrated that $\mathrm{S}_{\mathrm{S}}$ must be sufficiently high in order to ensure appropriate turbulence in the extractor, which would entail increased mass transfer rate and increased polyphenol diffusivity [23].

The proportion of DES and water is another key parameter related with the extraction of OLL polyphenols and this has been unequivocally demonstrated by recent studies [24-26]. The optimum $C_{\mathrm{DES}}$ of $78 \%(\mathrm{w} / \mathrm{v})$ that was determined in this study matched almost exactly the optimal value previously found $(80 \% \mathrm{w} / \mathrm{v})$ for a DES composed of glycerol/glycine/water (7:1:3) [25]. By contrast, for DES composed of glycerol/sodium-potassium tartrate/water (7:1:2) [26] and ethylene glycol/choline chloride (2:1) [24], the optimum $C_{\text {DES }}$ was $50 \%$ (v/v). Despite the different expression of concentration $(\mathrm{w} / \mathrm{v}$ versus $\mathrm{v} / \mathrm{v})$, it could be argued that significant differences may be seen, presumably attributed to the different nature of the DES used. DES constituents, as well as their molar proportion, may largely define characteristics of the DES that are crucial to extraction, including polarity and viscosity [15]. DES composed of organic acids and amino acids appear to be more polar than those composed of polyols. Therefore, these DES would require less amount of water for polarity regulation. This theory is consistent with recent findings, which demonstrated that the higher the lipophilicity of the HBA, the higher the amount of water required for maximum polyphenol recovery [27]. 

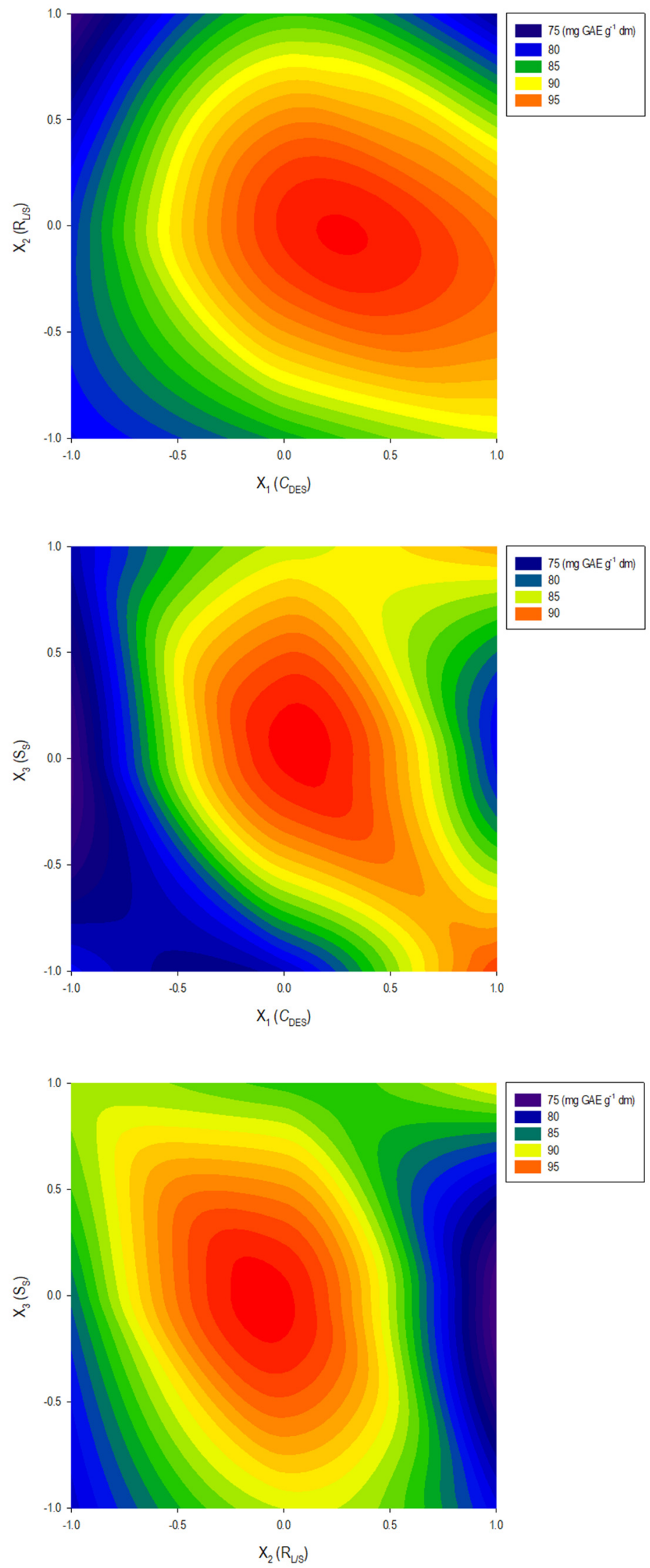

Figure 2. Contour plots illustrating the effect of variable covariation on the response $\left(\mathrm{Y}_{\mathrm{TP}}\right)$. Upper plot, covariation of $X_{1}$ and $X_{2}$; middle plot, covariation of $X_{1}$ and $X_{3}$; lower plot, covariation of $X_{2}$ and $X_{3}$. 


\subsection{Temperature Effects}

The issue related with the effect of temperature on the extraction performance has been a subject of several studies, which yielded contradictory results. In general, polyphenols are considered thermolabile substances and temperatures above $60-70{ }^{\circ} \mathrm{C}$ might not favor increased extraction yield $[28,29]$. However, this is not always the case, and other investigations demonstrated that extraction carried out up to $80^{\circ} \mathrm{C}$ might provide extracts with higher polyphenol concentration and improved antioxidant characteristics [30,31]. The effect of temperature on the polyphenol yield rather depends on the nature of the polyphenols of a given plant material, as well as the nature of the solvent used and other conditions (e.g., $\mathrm{pH}$ ). Therefore, for each methodology developed, the effect of temperature would be a subject of case experimentation.

To test such this hypothesis, extractions were performed at $80^{\circ} \mathrm{C}$, under optimized conditions, and the characteristics of the obtained extracts were compared with those of the extract that was produced at the working temperature $\left(50^{\circ} \mathrm{C}\right)$. The increase that was recorded for $\mathrm{Y}_{\mathrm{TP}}$ was rather marginal $(2.4 \%)$, but extraction at $80{ }^{\circ} \mathrm{C}$ resulted in a $26.4 \%$ increase in $\mathrm{Y}_{\mathrm{TFn}}, 17.6 \%$ in $\mathrm{A}_{\mathrm{AR}}$ and $11.8 \%$ in $\mathrm{P}_{\mathrm{R}}$ (Table 5). This is in line with studies on OLL extraction that demonstrated a progressive increase in $Y_{\mathrm{TP}}$, when $T$ was switched for 40 to $70{ }^{\circ} \mathrm{C}$ [25]. The extraction of OLL polyphenols with a combination of DES and $\beta$-cyclodextrin also showed increases in $\mathrm{Y}_{\mathrm{TP}}, \mathrm{Y}_{\mathrm{TF}}, \mathrm{A}_{\mathrm{AR}}$, and $\mathrm{P}_{\mathrm{R}}$, when $T$ varied from 23 to $80^{\circ} \mathrm{C}$ [17]. These findings are also consistent with the outcome of previous examinations, which showed that the optimal $T$ for OLL polyphenol extraction with DES was $73^{\circ} \mathrm{C}$ [26] and $79.8^{\circ} \mathrm{C}$ [24].

Table 5. Effect of extraction at $80{ }^{\circ} \mathrm{C}$ on total polyphenols $\left(\mathrm{Y}_{\mathrm{TP}}\right)$, total flavonoids $\left(\mathrm{Y}_{\mathrm{TFn}}\right)$, ferric-reducing power $\left(\mathrm{P}_{\mathrm{R}}\right)$, and antiradical activity $\left(\mathrm{A}_{\mathrm{AR}}\right)$ of the extracts produced with La-Gly (5:1), under optimized conditions.

\begin{tabular}{|c|c|c|c|c|}
\hline $\mathrm{T}\left({ }^{\circ} \mathrm{C}\right)$ & $\mathrm{Y}_{\mathrm{TP}}\left(\mathrm{mg} \mathrm{GAE} \mathrm{\textrm {g } ^ { - 1 } \mathrm { dm } )}\right.$ & $\mathrm{Y}_{\mathrm{TFn}}\left(\mathrm{mg} \mathrm{RtE} \mathrm{g}^{-1} \mathrm{dm}\right)$ & $\mathrm{A}_{\mathrm{AR}}\left(\mu \mathrm{mol} \mathrm{DPPH} \mathrm{g}^{-1} \mathrm{dm}\right)$ & $P_{R}\left(\mu \mathrm{mol}\right.$ AAE $\left.g^{-1} \mathrm{dm}\right)$ \\
\hline 50 & $96.41 \pm 2.27$ & $19.47 \pm 0.68$ & $637.14 \pm 11.57$ & $407.00 \pm 7.00$ \\
\hline 80 & $98.77 \pm 2.00$ & $26.44 \pm 0.98$ & $773.21 \pm 13.89$ & $461.18 \pm 8.11$ \\
\hline
\end{tabular}

By contrast, OLL polyphenol extraction with a blend of methyl $\beta$-cyclodextrin and a glycerol/glycine-based DES was shown to have $51{ }^{\circ} \mathrm{C}$ as the optimal $T$ [32]. Considering all of the above, it could be argued that OLL extraction might well be performed at $80^{\circ} \mathrm{C}$ to further enrich the resulting extract in flavonoids and improve its antioxidant properties.

The maximum $\mathrm{Y}_{\mathrm{TP}}$ that was attained at $80^{\circ} \mathrm{C}$ was $98.77 \pm 2.00 \mathrm{mg} \mathrm{GAE} \mathrm{g}^{-1} \mathrm{dm}_{\text {(Table 5). This }}$ level is close to the $109.93 \mathrm{mg} \mathrm{GAE} \mathrm{g}^{-1} \mathrm{dm}$ reported by previous studies on OLL from the same variety, produced using a glycerol/glycine DES, although it has also been demonstrated that a combination of that DES with methyl $\beta$-cyclodextrin might provide even higher $Y_{\mathrm{TP}}\left(116.58 \mathrm{mg} \mathrm{GAE} \mathrm{g}^{-1} \mathrm{dm}\right)$ [32]. A series of extraction methodologies involving intensification, such as microwave and ultrasound irradiation, as well as steam explosion and conventional volatile solvents, showed that $Y_{T P}$ from OLL might vary from 20.9 to $144.2 \mathrm{mg} \mathrm{GAE} \mathrm{g}^{-1} \mathrm{dm}$ [33]. In the light of these findings, the methodology proposed herein might be regarded as a rather high-performing process, which requires neither intensification nor volatile solvents.

\subsection{Polyphenolic Composition}

The examination of the polyphenolic composition was carried out for the extract that exhibited the highest $Y_{T P}, Y_{T F n}, A_{A R}$, and $P_{R}$, that is, for the extract produced under optimized conditions, at $80^{\circ} \mathrm{C}$. A typical HPLC trace, along with peak assignment, is given in Figure 3. LC-MS analysis was carried out to tentatively identify peak \#4. The peak gave a pseudo-molecular ion at $m / z=579 \mathrm{amu}$, a diagnostic adduct with $\mathrm{Na}^{+}$at $m / z=601 \mathrm{amu}$ and a fragment at $m / z=271 \mathrm{amu}$. Based on previous data [26], this peak was assigned to apigenin 7-O-rutinoside. Hydroxytyrosol (peak \#1) was the predominant constituent and its content amounted $8.20 \pm 0.12 \mathrm{mg} \mathrm{g}^{-1} \mathrm{dm}$. On the other hand, oleuropein had a content of $2.88 \pm 0.04 \mathrm{mg} \mathrm{g}^{-1} \mathrm{dm}$ (Table 6). Oleuropein is usually the most abundant OLL phytochemical 
and its content might vary from 3.2 to as high as $356 \mathrm{mg} \mathrm{g}^{-1} \mathrm{dm}$ [34]. Therefore, its relatively low content in conjunction with the presence of higher hydroxytyrosol levels raised suspicions regarding oleuropein stability. Methanol OLL extracts were also analyzed to verify such a hypothesis. The oleuropein content determined based on the methanolic extract was $13.46 \mathrm{mg} \mathrm{g}^{-1} \mathrm{dm}$, which was approximately 4.7 times higher than that determined from the DES extract, whereas the hydroxytyrosol content was almost six times lower.

Table 6. Yield of major polyphenolic phytochemicals obtained with La-Gly (5:1), under optimized conditions, at $80^{\circ} \mathrm{C}$.

\begin{tabular}{cc}
\hline Polyphenol & Content $\left.\mathbf{m g ~ g}^{-\mathbf{1}} \mathbf{d m}\right) \pm \mathbf{s d}$ \\
\hline Hydroxytyrosol & $8.20 \pm 0.12$ \\
Rutin & $0.28 \pm 0.00$ \\
Luteolin 7-O-glucoside & $2.59 \pm 0.04$ \\
Apigenin 7-O-rutinoside & $0.36 \pm 0.01$ \\
Luteolin 3'-O-glucoside & $0.36 \pm 0.01$ \\
Oleuropein & $2.88 \pm 0.04$ \\
Quercetin & $0.44 \pm 0.01$ \\
Apigenin & $0.01 \pm 0.00$ \\
Sum & 15.13 \\
\hline
\end{tabular}

This outcome demonstrated that oleuropein was not stable in the DES used and it was hydrolyzed, yielding hydroxytyrosol. This is in line with earlier examinations, which also revealed oleuropein hydrolysis in a glycerol/glycine DES, after 20 days of storage of the OLL extract at $50{ }^{\circ} \mathrm{C}$, and the formation of hydroxytyrosol [35]. However, in the case that is presented herein, it was evident that hydrolysis was far more drastic, since it occurred during $150 \mathrm{~min}$ of extraction. This finding is particularly interesting, indicating that the DES used might be a benign and effective means of oleuropein hydrolysis for the production of hydroxytyrosol, which might be a more potent antioxidant [36,37]. On this ground, it could be argued that the nature of DES could play a significant role regarding the stability of certain polyphenolic compounds. As this issue is largely unexamined, further and more detailed studies are required to clarify DES features that may be linked with polyphenol instability. This might lead to tuning DES as desired, to develop green methods for polyphenol modification with improved biological properties.

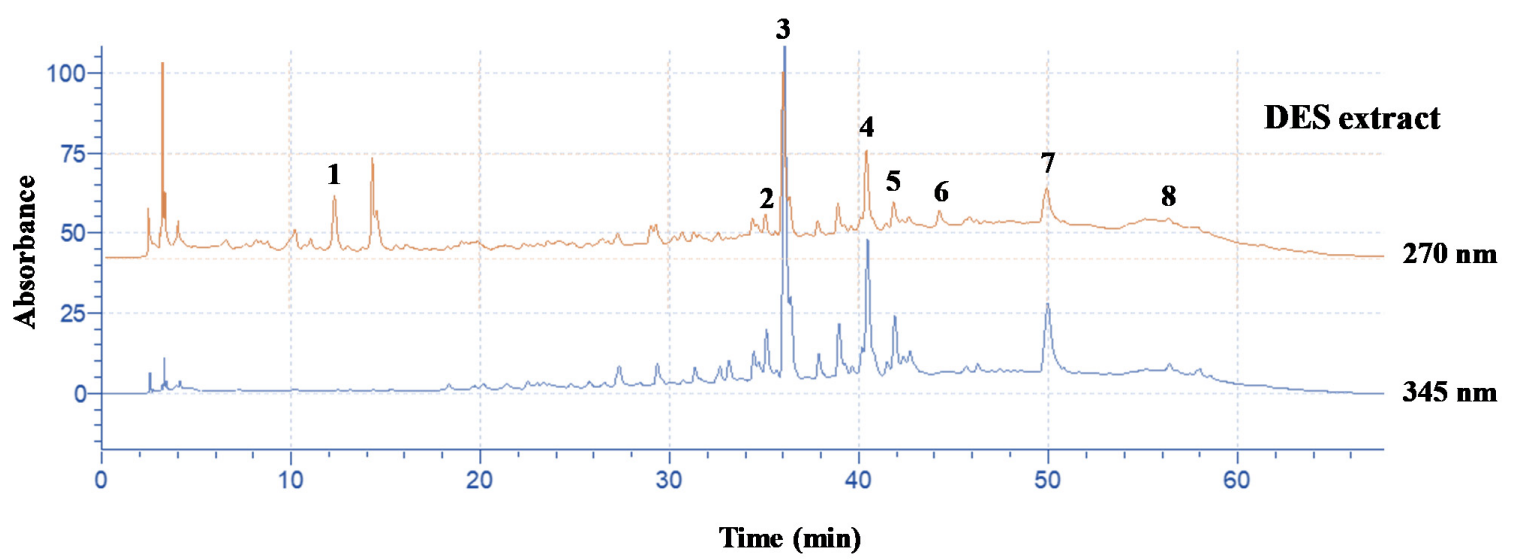

Figure 3. Cont. 


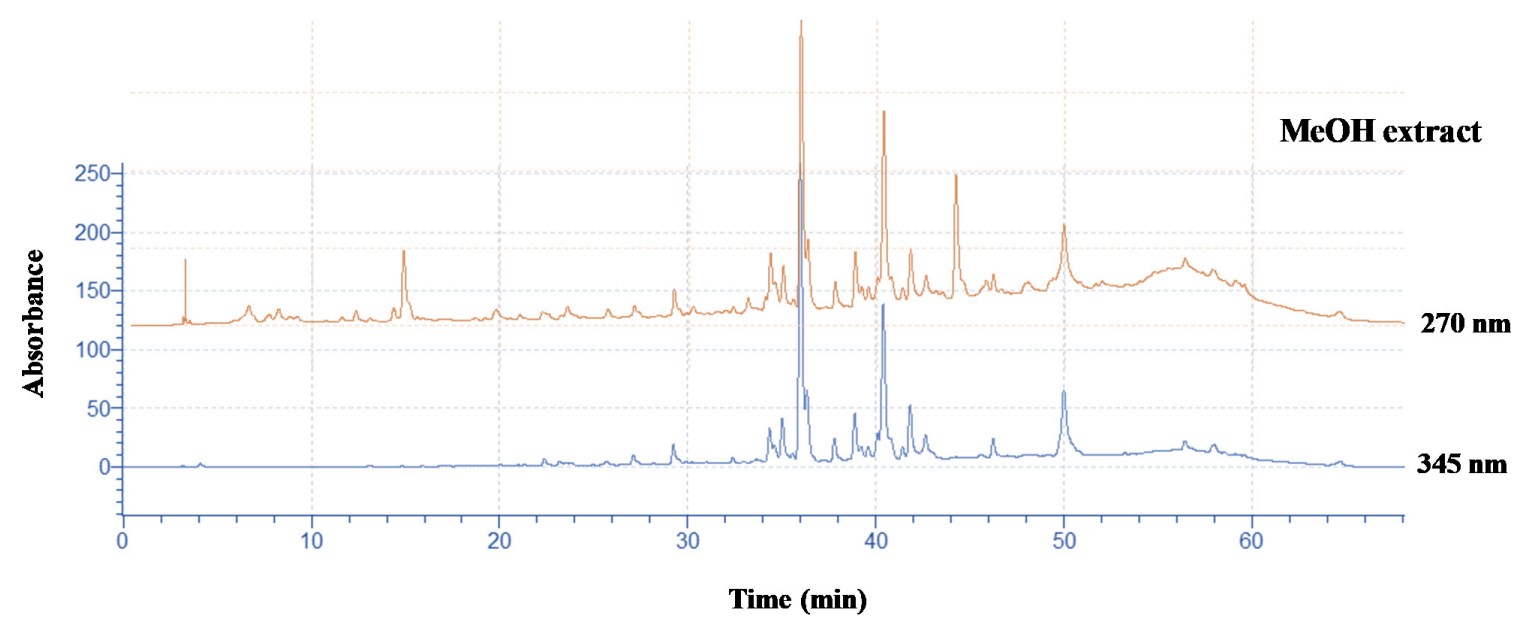

Figure 3. Chromatograms recorded at 270 and $345 \mathrm{~nm}$, showing major polyphenolic constituents of OLL extracts. The upper figure displays the profile of the DES extract obtained under optimized conditions, at $80{ }^{\circ} \mathrm{C}$ and the lower figure is the profile of a control extract obtained with $60 \%$ methanol, at room temperature. Peak assignment: 1, hydroxytyrosol; 2 , rutin;, 3, luteolin 7-O-glucoside; 4, apigenin 7-O-rutinoside; 5, luteolin 3'-O-glucoside; 6, oleuropein; 7, quercetin; and, 8, apigenin.

\section{Conclusions}

The use of a recently developed DES based on L-lactic acid and glycine was shown to be highly effective for the recovery of OLL polyphenols. Following the implementation of response surface methodology, the optimized extraction conditions were $C_{\mathrm{DES}}=78 \%(\mathrm{w} / \mathrm{v}), \mathrm{R}_{\mathrm{L} / \mathrm{S}}=36 \mathrm{~mL} \mathrm{~g}^{-1}$, and $\mathrm{S}_{\mathrm{S}}=500 \mathrm{rpm}$. The examination of temperature effects showed that extraction might well be performed at $80^{\circ} \mathrm{C}$ to produce extracts with enhanced flavonoid content and increased antioxidant activity. The extraction with the DES used was demonstrated to extensively hydrolyze oleuropein, yielding hydroxytyrosol. This finding might be of importance, in the view of targeted polyphenol modification for the generation of more biopotent derivatives.

Author Contributions: O.K., S.G., A.L., and E.B. carried out the experimentation and handled the raw data. S.L. and D.P.M. conceived the idea, designed the experiment, performed statistics, handled the data and wrote the paper. All authors have read and agreed to the published version of the manuscript.

Funding: This research was co-financed by the European Union and the Hellenic Ministry of Economy \& Development through the Operational Programme Competitiveness, Entrepreneurship and Innovation, under the call RESEARCH—CREATE-INNOVATE (project code: T1EDK-05677).

Conflicts of Interest: The authors declare no conflict of interest.

\section{Nomenclature}

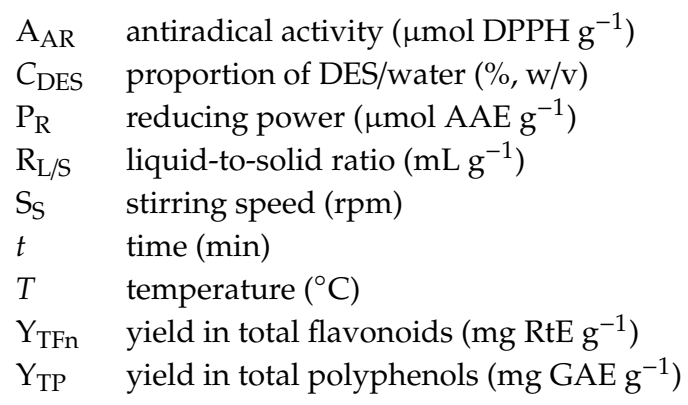




\section{Abbreviations}

$\begin{array}{ll}\text { AAE } & \text { ascorbic acid equivalents } \\ \text { DPPH } & \text { 2,2-diphenyl-1-picrylhydrazyl radical } \\ \text { GAE } & \text { gallic acid equivalents } \\ \text { Gly } & \text { glycine } \\ \text { HBA } & \text { hydrogen bond acceptor } \\ \text { HBD } & \text { hydrogen bond donor } \\ \text { LA } & \text { lactic acid } \\ \text { OLL } & \text { olive leaves } \\ \text { TPTZ } & \text { 2,4,6-tripyridyl-s-triazine }\end{array}$

\section{References}

1. Pfaltzgraff, L.A.; Cooper, E.C.; Budarin, V.; Clark, J.H. Food waste biomass: A resource for high-value chemicals. Green Chem. 2013, 15, 307-314. [CrossRef]

2. Zuin, V.G.; Ramin, L.Z. Green and sustainable separation of natural products from agro-industrial waste: Challenges, potentialities, and perspectives on emerging approaches. In Chemistry and Chemical Technologies in Waste Valorization; Springer: Berlin/Heidelberg, Germany, 2018; pp. 229-282.

3. Chemat, F.; Abert Vian, M.; Ravi, H.K.; Khadhraoui, B.; Hilali, S.; Perino, S.; Fabiano Tixier, A.-S. Review of alternative solvents for green extraction of food and natural products: Panorama, principles, applications and prospects. Molecules 2019, 24, 3007. [CrossRef] [PubMed]

4. Torres-Valenzuela, L.S.; Ballesteros-Gómez, A.; Rubio, S. Green solvents for the extraction of high added-value compounds from agri-food waste. Food Eng. Rev. 2019, 12, 83-100. [CrossRef]

5. Vanda, H.; Dai, Y.; Wilson, E.G.; Verpoorte, R.; Choi, Y.H. Green solvents from ionic liquids and deep eutectic solvents to natural deep eutectic solvents. Comptes Rendus Chim. 2018, 21, 628-638. [CrossRef]

6. Skarpalezos, D.; Detsi, A. Deep eutectic solvents as extraction media for valuable flavonoids from natural sources. Appl. Sci. 2019, 9, 4169. [CrossRef]

7. Peralbo-Molina, Á.; de Castro, M.D.L. Potential of residues from the Mediterranean agriculture and agrifood industry. Trends Food Sci. Technol. 2013, 32, 16-24. [CrossRef]

8. Lakka, A.; Grigorakis, S.; Karageorgou, I.; Batra, G.; Kaltsa, O.; Bozinou, E.; Lalas, S.; Makris, D.P. Saffron processing wastes as a bioresource of high-value added compounds: Development of a green extraction process for polyphenol recovery using a natural deep eutectic solvent. Antioxidants 2019, 8, 586. [CrossRef]

9. Mylonaki, S.; Kiassos, E.; Makris, D.P.; Kefalas, P. Optimisation of the extraction of olive (Olea europaea) leaf phenolics using water/ethanol-based solvent systems and response surface methodology. Anal. Bioanal. Chem. 2008, 392, 977. [CrossRef]

10. Lakka, A.; Karageorgou, I.; Kaltsa, O.; Batra, G.; Bozinou, E.; Lalas, S.; Makris, D. Polyphenol extraction from Humulus lupulus (hop) using a neoteric glycerol/L-alanine deep eutectic solvent: Optimisation, kinetics and the effect of ultrasound-assisted pretreatment. AgriEngineering 2019, 1, 403-417. [CrossRef]

11. Lakka, A.; Grigorakis, S.; Kaltsa, O.; Karageorgou, I.; Batra, G.; Bozinou, E.; Lalas, S.; Makris, D.P. The effect of ultrasonication pretreatment on the production of polyphenol-enriched extracts from Moringa oleifera $\mathrm{L}$. (drumstick tree) using a novel bio-based deep eutectic solvent. Appl. Sci. 2020, 10, 220. [CrossRef]

12. Cicco, N.; Lanorte, M.T.; Paraggio, M.; Viggiano, M.; Lattanzio, V. A reproducible, rapid and inexpensive Folin-Ciocalteu micro-method in determining phenolics of plant methanol extracts. Microchem. J. 2009, 91, 107-110. [CrossRef]

13. Manousaki, A.; Jancheva, M.; Grigorakis, S.; Makris, D. Extraction of antioxidant phenolics from agri-food waste biomass using a newly designed glycerol-based natural low-transition temperature mixture: A comparison with conventional eco-friendly solvents. Recycling 2016, 1, 194-204. [CrossRef]

14. Paleologou, I.; Vasiliou, A.; Grigorakis, S.; Makris, D.P. Optimisation of a green ultrasound-assisted extraction process for potato peel (Solanum tuberosum) polyphenols using bio-solvents and response surface methodology. Biomass Convers. Bioref. 2016, 6, 289-299. [CrossRef]

15. Karakashov, B.; Grigorakis, S.; Loupassaki, S.; Makris, D.P. Optimisation of polyphenol extraction from Hypericum perforatum (St. John's Wort) using aqueous glycerol and response surface methodology. J. Appl. Res. Med. Aromat. Plants 2015, 2, 1-8. [CrossRef] 
16. Dai, Y.; Witkamp, G.-J.; Verpoorte, R.; Choi, Y.H. Tailoring properties of natural deep eutectic solvents with water to facilitate their applications. Food Chem. 2015, 187, 14-19. [CrossRef]

17. Chakroun, D.; Grigorakis, S.; Loupassaki, S.; Makris, D.P. Enhanced-performance extraction of olive (Olea europaea) leaf polyphenols using L-lactic acid/ammonium acetate deep eutectic solvent combined with $\beta$-cyclodextrin: Screening, optimisation, temperature effects and stability. Biomass Convers. Bioref. 2019. [CrossRef]

18. Stefou, I.; Grigorakis, S.; Loupassaki, S.; Makris, D.P. Development of sodium propionate-based deep eutectic solvents for polyphenol extraction from onion solid wastes. Clean Technol. Environ. Policy 2019, 21, 1563-1574. [CrossRef]

19. Cacace, J.; Mazza, G. Mass transfer process during extraction of phenolic compounds from milled berries. J. Food Eng. 2003, 59, 379-389. [CrossRef]

20. Ho, C.H.; Cacace, J.E.; Mazza, G. Mass transfer during pressurized low polarity water extraction of lignans from flaxseed meal. J. Food Eng. 2008, 89, 64-71. [CrossRef]

21. Rakotondramasy-Rabesiaka, L.; Havet, J.-L.; Porte, C.; Fauduet, H. Estimation of effective diffusion and transfer rate during the protopine extraction process from Fumaria officinalis L. Sep. Purif. Technol. 2010, 76, 126-131. [CrossRef]

22. Pinelo, M.; Zornoza, B.; Meyer, A.S. Selective release of phenols from apple skin: Mass transfer kinetics during solvent and enzyme-assisted extraction. Sep. Purif. Technol. 2008, 63, 620-627. [CrossRef]

23. Shewale, S.; Rathod, V.K. Extraction of total phenolic content from Azadirachta indica or (neem) leaves: Kinetics study. Prep. Biochem. Biotech. 2018, 48, 312-320. [CrossRef] [PubMed]

24. Alañón, M.E.; Ivanović, M.; Gómez-Caravaca, A.M.; Arráez-Román, D.; Segura-Carretero, A. Choline chloride derivative-based deep eutectic liquids as novel green alternative solvents for extraction of phenolic compounds from olive leaf. Arabian J. Chem. 2018, 13, 1685-1701. [CrossRef]

25. Athanasiadis, V.; Grigorakis, S.; Lalas, S.; Makris, D.P. Highly efficient extraction of antioxidant polyphenols from Olea europaea leaves using an eco-friendly glycerol/glycine deep eutectic solvent. Waste Biomass Valorif. 2018, 9, 1985-1992. [CrossRef]

26. Dedousi, M.; Mamoudaki, V.; Grigorakis, S.; Makris, D.P. Ultrasound-assisted extraction of polyphenolic antioxidants from olive (Olea europaea) leaves using a novel glycerol/sodium-potassium tartrate low-transition temperature mixture (LTTM). Environments 2017, 4, 31. [CrossRef]

27. Slim, Z.; Jancheva, M.; Grigorakis, S.; Makris, D.P. Polyphenol extraction from Origanum dictamnus using low-transition temperature mixtures composed of glycerol and organic salts: Effect of organic anion carbon chain length. Chem. Eng. Commun. 2018, 205, 1494-1506. [CrossRef]

28. Khiari, Z.; Makris, D.P.; Kefalas, P. An investigation on the recovery of antioxidant phenolics from onion solid wastes employing water/ethanol-based solvent systems. Food Bioprocess Technol. 2009, 2, 337. [CrossRef]

29. Shang, X.; Dou, Y.; Zhang, Y.; Tan, J.-N.; Liu, X.; Zhang, Z. Tailor-made natural deep eutectic solvents for green extraction of isoflavones from chickpea (Cicer arietinum L.) sprouts. Ind. Crops Prod. 2019, 140, 111724. [CrossRef]

30. Shehata, E.; Grigorakis, S.; Loupassaki, S.; Makris, D.P. Extraction optimisation using water/glycerol for the efficient recovery of polyphenolic antioxidants from two Artemisia species. Sep. Purif. Technol. 2015, 149, 462-469. [CrossRef]

31. Jancheva, M.; Grigorakis, S.; Loupassaki, S.; Makris, D.P. Optimised extraction of antioxidant polyphenols from Satureja thymbra using newly designed glycerol-based natural low-transition temperature mixtures (LTTMs). J. Appl. Res. Med. Aromat. Plants 2017, 6, 31-40. [CrossRef]

32. Athanasiadis, V.; Grigorakis, S.; Lalas, S.; Makris, D.P. Methyl $\beta$-cyclodextrin as a booster for the extraction for Olea europaea leaf polyphenols with a bio-based deep eutectic solvent. Biomass Convers. Bioref. 2018, 8 , 345-355. [CrossRef]

33. Cifá, D.; Skrt, M.; Pittia, P.; Di Mattia, C.; Poklar Ulrih, N. Enhanced yield of oleuropein from olive leaves using ultrasound-assisted extraction. Food Sci. Nutr. 2018, 6, 1128-1137. [CrossRef]

34. Hassen, I.; Casabianca, H.; Hosni, K. Biological activities of the natural antioxidant oleuropein: Exceeding the expectation-A mini-review. J. Funct. Foods 2015, 18, 926-940. [CrossRef]

35. Athanasiadis, V.; Grigorakis, S.; Lalas, S.; Makris, D.P. Stability effects of methyl $\beta$-cyclodextrin on Olea europaea leaf extracts in a natural deep eutectic solvent. Eur. Food Res. Technol. 2018, 244, 1783-1792. [CrossRef] 
36. Briante, R.; La Cara, F.; Tonziello, M.P.; Febbraio, F.; Nucci, R. Antioxidant activity of the main bioactive derivatives from oleuropein hydrolysis by hyperthermophilic $\beta$-glycosidase. J. Agric. Food Chem. 2001, 49, 3198-3203. [CrossRef]

37. Yuan, J.-J.; Wang, C.-Z.; Ye, J.-Z.; Tao, R.; Zhang, Y.-S. Enzymatic hydrolysis of oleuropein from Olea europea (olive) leaf extract and antioxidant activities. Molecules 2015, 20, 2903-2921. [CrossRef]

(C) 2020 by the authors. Licensee MDPI, Basel, Switzerland. This article is an open access article distributed under the terms and conditions of the Creative Commons Attribution (CC BY) license (http://creativecommons.org/licenses/by/4.0/). 